\title{
A Study on the Challenges Being Faced by Chandigarh University Students and their Parents during Covid-19 Lockdown
}

\author{
Sonika Kanojia \\ Assistant Professor, University School of Business-Industry Collaborated Programs, Chandigarh University, Mohali-140413 \\ Punjab, India
}

Article History: Received: 11 January 2021; Accepted: 27 February 2021; Published online: 5 April 2021

\begin{abstract}
These days when India is locked down, apart from the economy the hardest thing getting suffered is our students' education. They were in the midst of their classes or examination when this Covid-19 a coronavirus attacked India. Very wisely the India government took the decision to lockdown whole India in very initial stage. Chandigarh University management announced postponing the exams and immediately asked the students to move to their homes, if possible. This decision was taken one week in advance to the Indian Government decision. It was on 14th of March, 2020 when the management of the University decided the wellbeing of their students and asked them to move back. With this effort, most of the students reached their homes and staying with their parents. In all this set back an emotional support is very necessary. This study was initiated to understand the physical and emotional wellbeing of the students of Chandigarh University. The results found are very positive as most of the students are safe including those who could not leave their hostels because of any reason. They are being taken good care by Chandigarh University Management. In this study, we have tried to find out if the students are facing any challenges and if they are worried for anything. It will support the management to put their best effort forward to make the things even better for the students. The student strength of Chandigarh University belongs to complete India so this study will help all educational institutions to better support their students.
\end{abstract}

\section{Introduction}

Corona virus disease (COVID-19) is an infectious disease caused by a new virus. The disease causes respiratory illness (like the flu) with symptoms such as a cough, fever, and in more severe cases, difficulty breathing. You can protect yourself by washing your hands frequently, avoiding touching your face, and avoiding close contact (1 meter or 3 feet) with people who are unwell. Corona virus disease spreads primarily through contact with an infected person when they cough or sneeze. It also spreads when a person touches a surface or objects that has the virus on it, and then touches their eyes, nose, or mouth. This disease started from China and infected the whole world in almost 6 months. On 30th January, 2020 India reported the first case in Kerala which rose to 3 cases by 3rd Feb, 2020. Slowly the impact of the virus was across the states. When the first case was reported in Punjab, Chandigarh University management decided to postpone the mid-term examination. It was supposed to start on 16th March, 2020. But University announced postponing the exams and asked the students to leave for their homes if it was comfortable to them. They supported in all forms to make the students catch their buses, trains or flights in time to reach their homes safely. Only the foreign students or few other students who did not have any conveyance to travel stayed back at the hostel. The students at the hostel are also being taken care by the university in a well versed manner.

\section{Objective of the study}

- To understand the emotional level of the students of Chandigarh University during this Covid-19 lockdown.

- To know the challenges being faced by the students and their worries in this period.

- To understand the worries of parents in this lockdown period.

3. Benefits of the study

- To know the emotional level of the students and take appropriate steps to improve their mental condition if required.

- To understand the challenges being faced by students to cover up their studies and how to better utilize their time at home. University will be able to guide them better.

- When the University know their worries, the management can prepare themselves better for the after lockdown period.

\section{Area of Study:}

Chandigarh University, which itself serves as a mini-cosmopolitan, with students coming from all diverse backgrounds and part of the country and from foreign nations, has been selected as the area of study. This will help in getting the data from all the major customer group and vis-à-vis lower income group, middle income group and upper income group.

\section{Analysis}

To conduct this research a questionnaire was prepared and it was responded by 834 students of different streams of Chandigarh University. They are from undergraduate and post graduate programs. 


\section{Where are you right now?}

834 responses

\section{Graph: 1}

The first question replied us that approximately $94 \%$ students have safely reached home. $3.1 \%$ are in hostel and $1 \%$ are in PG and just $2 \%$ left from hostel but could not reach their home and staying in some shelter.

\section{Are you able to understand the disease? \\ 834 responses}

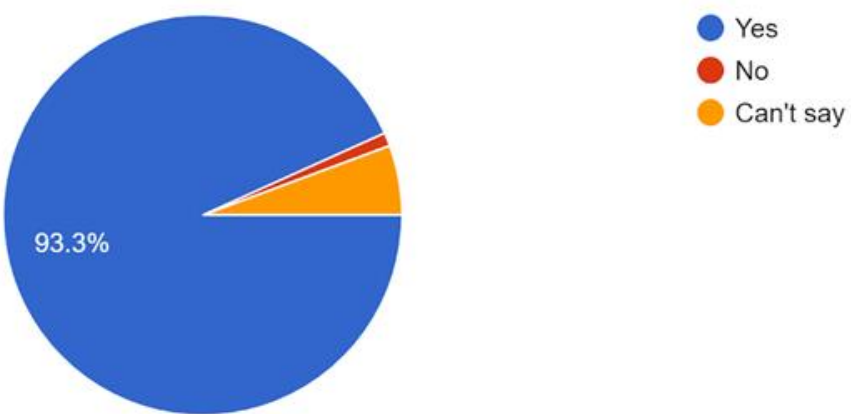

Graph: 2

Only $6.7 \%$ students are in the state to not understand the disease properly. As per the analysis most of these students who have not understood the disease are at home. All the hostel living students are well aware of the disease and its spread.

But in parents graph 1 on next page shows that the percentage of not knowing the decease is only $4 \%$.

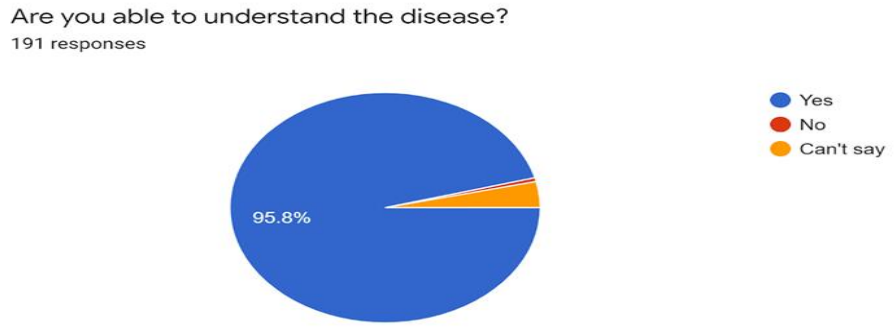

Parents Graph: 1

From the below graph, it is understood that only $51.3 \%$ students have good internet connectivity at their place. All the students staying at hostel are receing proper network as per the survey. 


\section{Do you have proper internet connection?}

834 responses

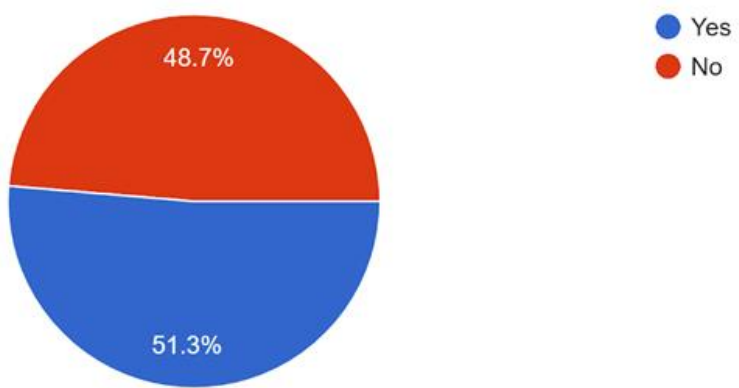

Graph: 3

What words can explain your feeling the best during this lock down period? 834 responses

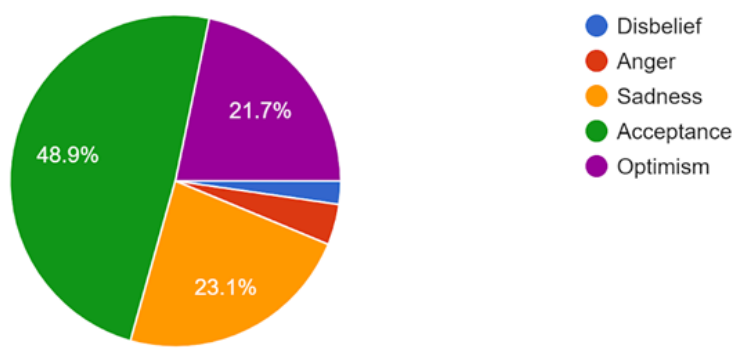

Graph: 4

What words can explain your feeling the best during this lock down period? 191 responses

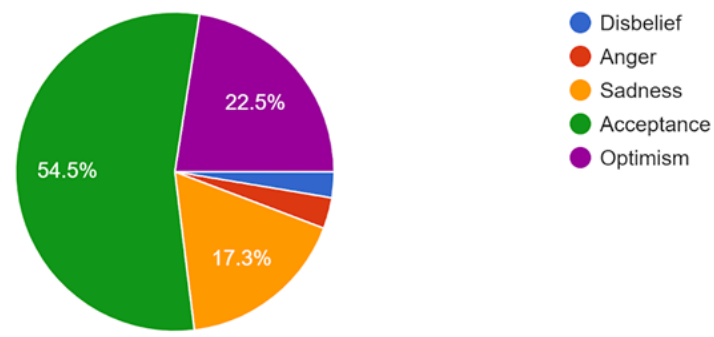

Parents graph: 2

Anne Marie Collins who is President of the Australian Association of Psychologists in Melbourne, Victoria, where she works with patients who are battling personal trauma and difficult family circumstances, revealed 5 stages people experience during lockdown. According to her the first stage is disbelief followed by anger, sadness, acceptance and optimism.

As per our study $70 \%$ of our students have already reached the stage of acceptance and optimism. With the parents this percentage is $75 \%$. Only $4 \%$ are in anger and $2.5 \%$ are in disbelief. The anger arises because of loss of control over our lives. Most of students have accepted the lockdown and extensive situation this has brought to their lives.

As per Ms. Collins this hopeful, optimistic state is where we're able to be more creative about how to make this situation work for us - the constructive, productive part of our brain is open for work again.

With this survey we get to know that $22 \%$ of our students have become optimistic about the situation and have found out the ways to constructively fight this pandemic in their lives.

https://www.dailymail.co.uk/femail/article-8190399/The-five-emotional-stages-coronavirus-lockdown-impactmental-health.html 
Are your teachers conducting online sessions?

834 responses

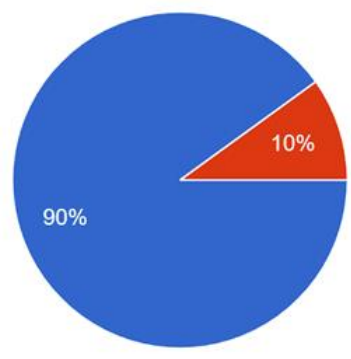

Yes

No

\section{Graph: 5}

Have you received sufficient material to get yourself prepared for the classes missed during the lockdown period?

834 responses
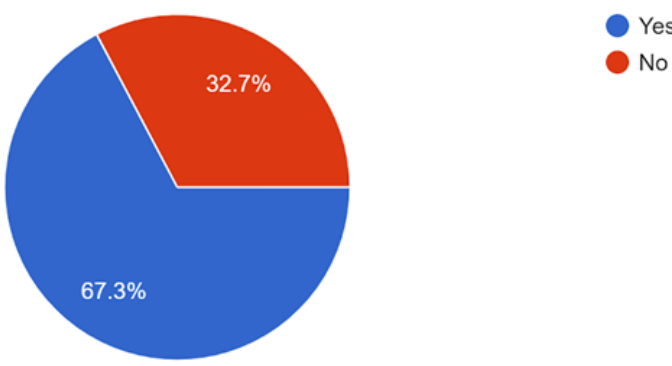

\section{Graph: 6}

In the Graph: 5, 90\% of the students have their teachers conducting online sessions to teach and cover their syllabus. In Graph 6, 32.7\% students say that they have not received sufficient self study material. Though, those who don't have their online classes going on, have higher percentage of $52 \%$ for not even receiving the self-study material.

This percentage is also higher for the students with less network connection and it is $45 \%$ of the total students who don't have online network in comparison to $21 \%$ of those who have online network. So we can relate that maybe because these students do not have proper internet connection is the reason for not receiving sufficient reading material.

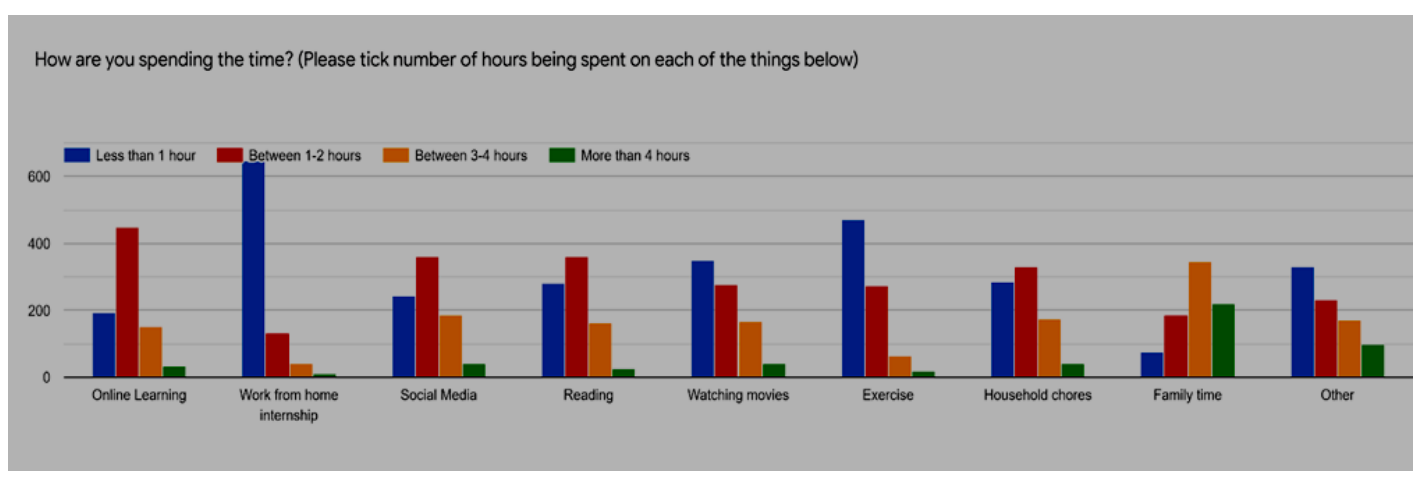

Graph:7

In the graph 7 , the analysis is being done on the time spent by students on different tasks. Though very few students are regularly spending time on work from home internship but many are spending sufficient time divided into online learning, reading, exercise etc. They are also able to balance lives with fun times and family times. Though, $80 \%$ students are spending more than 1 hour on social media also.

Once we can say that $90 \%$ are able to spend good family time more than 1 hour a day, on the other hand they are getting habitual of spending major part of their time on social media also. The family time is helping them maintain their emotional level and maybe social media is another way they found keep connected with their friends. 
What is worrying you most? (Give a rating from 1 to 5,1 being least worried and 5 being most worried)

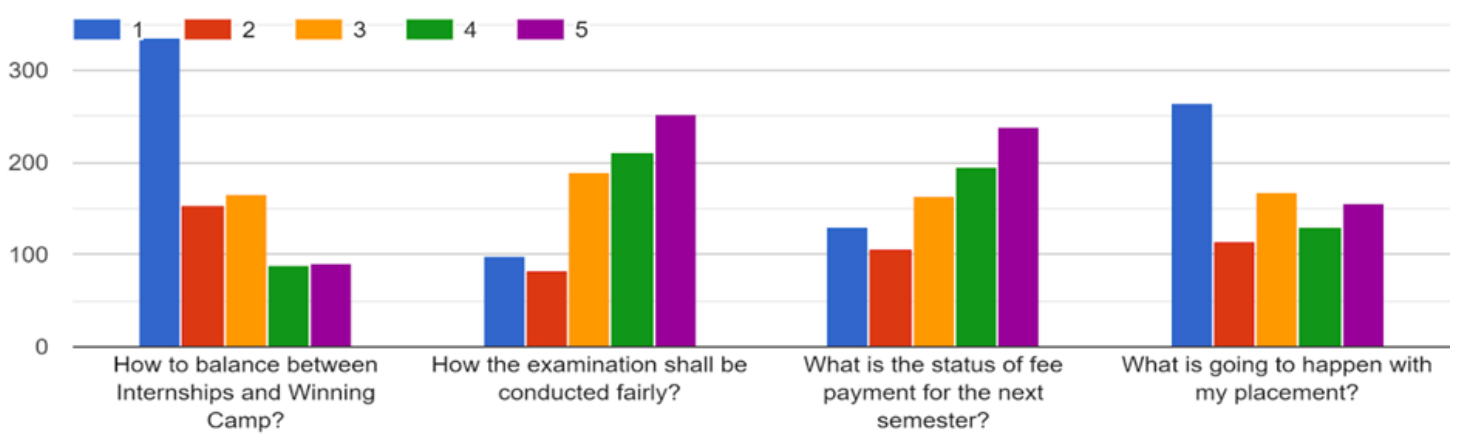

Graph: 8

In this question, it was tried to find out the worries of students during this lockdown period. They were given 4 topics that they can be worried for and asked the weightage for each point. In graph 8 , it is shown that only $22 \%$ students have their major worry of their internship and winning camp. 56\% students are most worried for the fair conduct of examination. 52\% are worried for the fee payment of next semester and $34 \%$ of students have their major worry of placements.

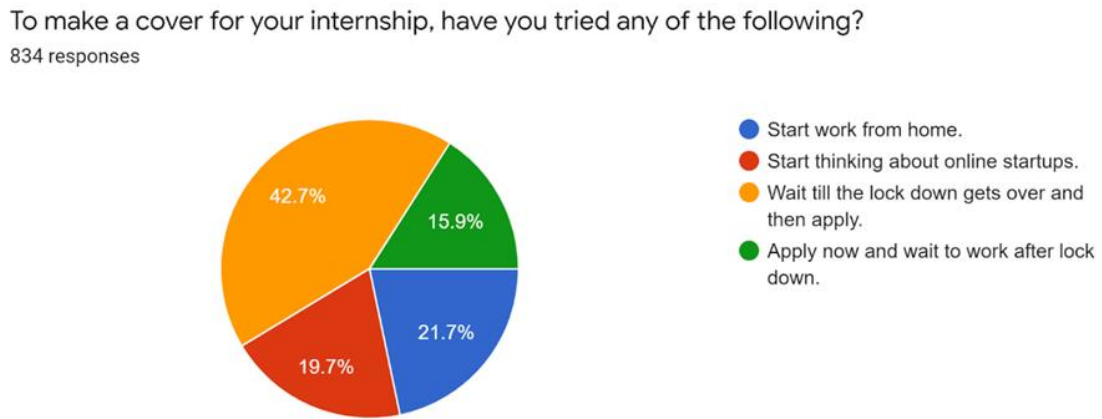

Graph: 9

Irrespective of they are worried for their internship or not, only $22 \%$ have started working from home on any project. 20\% are planning for an online start-up and rest are waiting for the lockdown to get over.

But a limitation to these two questions is that their year of studies is not clear in this study. So very difficult to say whether all students needed internship or not. But students could have utilized this time by actively doing some work from home internship. This could have added to their profiles from the perspective of their upcoming professional life.

Are you prepared to join as soon as the lock down is over? 834 responses

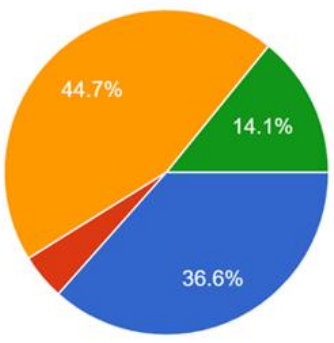

Yes by maintaining the social distance,

Yes without any distancing as I am missing my friends.

No, as I want the absolute clearance from Govt.

No, because I need to book my travel first

Graph: 10 


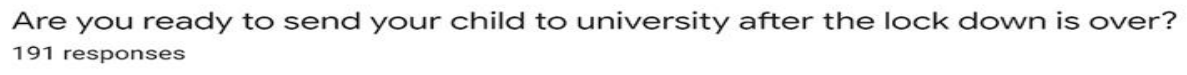
191 responses

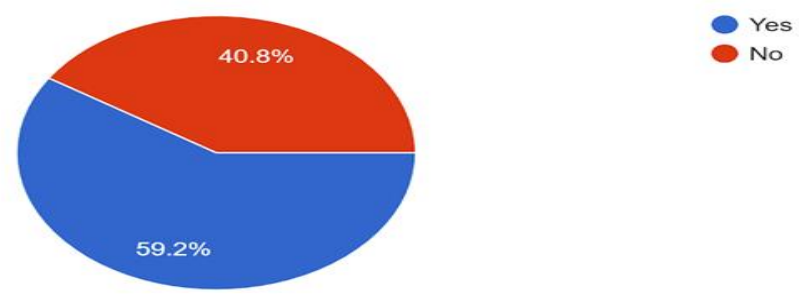

Parents graph: 3

In the last question, the effort was made to understand if the students are ready to join the university back as soon as the lockdown is over or not. In graph 10, we can understand that approximately $40 \%$ students are ready to physically join back the campus. But if we see the parents perspective then we can say that $59 \%$ parents are ready to send their children to campus after the lockdown is over. In another question it was found that 59\% parents consider Chandigarh University is a safe place after lockdown. In below graph we can see that 50\% parents are in favour of extending the lock down till the condition are absolutely better. These answers can be reviewed as parents know and believe that Chandigarh University campus will be a safe place but their children will have to travel from far areas to reach university and that is worrisome.

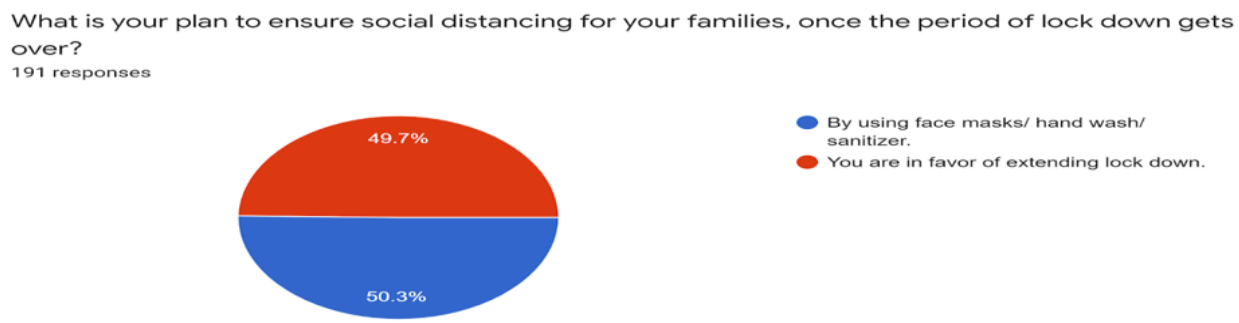

Parents graph: 4

Parents were additionally asked about the income level being affected due this lockdown. In the parents graph 5 it is found that about $37 \%$ parents have got their income affected due to the lockdown. And that is one of reasons for some of the students and parents being worried for the fee payment of upcoming semester and asking for some relief in terms of extending the period and giving some discount.
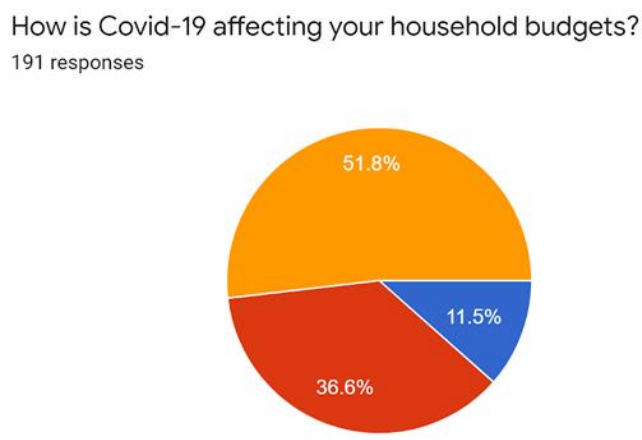

Not impacting at all
Impacting to large extent
Moderate

\section{Parents graph: 5}

Apart from above question, the students were asked to give one question that they want university management to reply or a suggestion for the management. Following points were highlighted by these students. (Sequenced in the most asked to less asked)

1. How is the examination going to be conducted? Some clarity should be given on this.

2. The payment of next semester fees should be postponed and some relaxation should be given in the amount of fees as well.

3. All practical courses should have some classes to be conducted before the final exams so that they can understand what theoretically could not be learnt.

4. Once the lockdown is over, sufficient time should be given to students to get their tickets booked and travel back to University 
5. Some international students are stranded on airports or embassy, whenever the lockdown gets over they will be sent back to their home country. How will their exams be conducted? Should they travel back or they should come back to university?

6. Students want to know the steps Chandigarh University is going to take to maintain social distancing during the classes and sanitization of the campus also.

\section{Conclusion of the study}

From the study, it can be said that the students of Chandigarh University are emotionally strong in this difficult time and they have involved themselves in various activities including self-study, reading, online learning, family time, Social media and some fun time as well. They have been able to involve themselves into theoretical learning through online sessions and material received from university faculty.

Amidst of all this the students are also worried for their studies, exam, placement and future of this year's education and fee payment.

From the parents perspective, the most 3 issues they have in their mind are

1. Internal and external examination of their children

2. Fee payment. Many of them do not know that they can pay online fees also.

3. Screening of all the students and staff after they join back the university. And other measures university is going to take.

\section{Recommendations}

Chandigarh University management can take following steps to clarify the situation better to students.

1. Encourage all students to undergo some online work from home internship project which can be full time or part time. CRC department should tie up with some companies which can hire our students in different departments for some handy experience which will help all students by adding value to their profile

2. Some firm decision should be drafted for the practical exams, attendance and other internal evaluation components and a formal communication can be given to students to get away with the confusion

3. As many students are spending good time on social media, they can be involved into some social media related activities only. These can be an online competition or some picture or video sharing campaign etc.

4. Some videos of sanitizing the campus can be shared on social media platforms so that students and their parents are pretty sure of the safety of the campus whenever they join back.Some awareness should be spread about the online fee payment facility.

5. Some FAQs can be rolled out with the answers. These FAQs can be made from the above points highlighted by students

\section{References}

1. https://www.dailymail.co.uk/femail/article-8190399/The-five-emotional-stages-coronavirus-lockdownimpact-mental-health.html

2. https://www.who.int/emergencies/diseases/novel-coronavirus-2019

3. https://bmcpublichealth.biomedcentral.com/articles/10.1186/1471-2458-10-130

4. https://www.weforum.org/agenda/2020/03/3-ways-coronavirus-is-reshaping-education-and-whatchanges-might-be-here-to-stay/

5. https://www.edutopia.org/article/covid-19s-impact-students-academic-and-mental-well-being 